\title{
Preparation and dielectric properties of $\left(\mathrm{Na}_{0.5} \mathrm{~K}_{0.5}\right) \mathrm{NbO}_{3}$ ceramics with $\mathrm{ZnO}$ and $\mathrm{CdO}$ addition
}

\author{
Barbara Garbarz-Glos ${ }^{a}$, Grzegorz Klimkowski ${ }^{b}$, Włodzimierz Śmiga ${ }^{a}$, \\ Maija Antonovac, and Anna Kalvane ${ }^{c}$

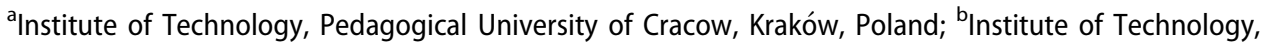 \\ The Jan Grodek State Vocational Academy in Sanok, Sanok, Poland; 'Institute of Solid State Physics, \\ University of Latvia, Riga, Latvia
}

\begin{abstract}
The sintering conditions, phase structure, and electrical properties of the $\mathrm{ZnO}$ and $\mathrm{CdO}$ doped $\left(\mathrm{Na}_{0.5} \mathrm{~K}_{0.5}\right) \mathrm{NbO}_{3}(\mathrm{NKN})$ ceramics were investigated and discussed. All the samples were prepared by a solid state reaction method. The addition of $1 \mathrm{wt} \% \mathrm{CdO}$ and $\mathrm{ZnO}$ as a sintering aid increases the density and lowering the sintering temperature. XRD analysis indicated perovskite structure with monoclinic symmetry. The investigated samples are good quality, the grains are well shaped without a glassy phase. The results of dielectric measurements revealed, that the dielectric properties of NKN based ceramics are stable in the wide temperature range.
\end{abstract}

\section{ARTICLE HISTORY}

Received 2 October 2018

Accepted 8 February 2019

\section{KEYWORDS}

Solid state sintering; sodium potassium niobate; dielectric properties

\section{Introduction}

$\mathrm{ABO}_{3}$-type compounds with perovskite structure are one of the most interesting group of materials. Among them, niobates hold the attention from the point of view of fundamental research, as well as of their possible applications. Especially, the potassium sodium niobate ceramics with attractive dielectric properties and high piezoelectric coefficients are considered as one of the most perspective candidates to replace highly effective lead-based materials. The main advantage of $\left(\mathrm{Na}_{0.5} \mathrm{~K}_{0.5}\right) \mathrm{NbO}_{3}$ is high phase transition temperature (close to $670 \mathrm{~K}$ ) in comparison with others lead-free materials with perovskite structure. $\left(\mathrm{Na}_{0.5} \mathrm{~K}_{0.5}\right) \mathrm{NbO}_{3}(\mathrm{NKN})$ is a solid solution of antiferroelectric sodium niobate $\mathrm{NaNbO}_{3}$ and ferroelectric potassium niobate $\mathrm{KNbO}_{3}$. Pure $\mathrm{NaNbO}_{3}$ undergoes several structural transitions from cubic Pm3m occurring above $913 \mathrm{~K}$; tetragonal P4/mbm (913-848 K); orthorhombic Ccmm (848-793 K) and Pnmm (793-753 $\mathrm{K}$ ), trough the antiferroelectric orthorhombic $\mathrm{Pbcm}$ phase to the low temperature (below $173 \mathrm{~K}$ ) ferroelectric rhombohedral $R 3 c$ phase [1-4]. On the other hand, potassium niobate $\mathrm{KNbO}_{3}$ transforms from the cubic (space group $P m 3 m$ ) to the tetragonal structure $P 4 \mathrm{~mm}$ at $709 \mathrm{~K}$ (below this temperature it exhibits a ferroelectric state), from the tetragonal to the orthorhombic phase $(\mathrm{Amm} 2)$ at $498 \mathrm{~K}$ and from orthorhombic to rhombohedral phase $(R 3 m)$ at $263 \mathrm{~K}$ [5]. $\mathrm{NaNbO}_{3}$ exhibits a large variety of interesting physical properties which can be changed by composition-induced structural modifications, such 
us the substitution of sodium $(\mathrm{Na})$ by potassium $(\mathrm{K})$ or lithium $(\mathrm{Li})$; therefore, materials with varying composition were developed and produced to adapt the material for a specific purpose [6-9]. At present, the main problem concerning $\mathrm{NKN}$ is a sintering process. The principal difficulty is to get samples with a high density (compared to leadbased materials) by using a conventional ceramic technology among others due to the high volatility of alkaline elements at high temperatures. The densification process and thermal treatment applied in the synthesis procedure of NKN has a decisive influence on its electrical properties. In this case, in order to produce a well-sintered, dense ceramic with one phase, doping with a low amount of alkaline earth elements as a sintering aid is necessary, which additionally contributes to lowering the sintering temperature $[10,11]$. The objective of this paper is to delineate the production of the dense ferroelectric material based on sodium potassium niobate NKN using conventional ceramic technology and to investigate the effects of the zinc oxide $\mathrm{ZnO}$ and cadmium oxide $\mathrm{CdO}$ addition on the sintering treatment, structure, microstructure and dielectric properties.

\section{Experimental procedure}

The stoichiometric composition of $\left(\mathrm{Na}_{0.5} \mathrm{~K}_{0.5}\right) \mathrm{NbO}_{3}$ was obtained by a conventional ceramic technology from the high purity powders potassium carbonate $\mathrm{K}_{2} \mathrm{CO}_{3}$, sodium carbonate $\mathrm{Na}_{2} \mathrm{CO}_{3}$, and niobium oxide $\mathrm{Nb}_{2} \mathrm{O}_{5}$. All the starting materials were weighed according to the chemical formula, homogenized and milled in an agate ball mill in absolute ethanol for $24 \mathrm{~h}$. After filtration, the material was calcined in an alumina crucible at the temperature $1123 \mathrm{~K}$ for $5 \mathrm{~h}$ in air. The synthesis of this material occurred as a solid state reaction given by the following formula: $1 / 2 \mathrm{Na}_{2} \mathrm{CO}_{3}+1 / 2 \mathrm{~K}_{2} \mathrm{CO}_{3}+\mathrm{Nb}_{2} \mathrm{O}_{5}$ $\rightarrow 2\left(\mathrm{Na}_{0.5} \mathrm{~K}_{0.5}\right) \mathrm{NbO}_{3}+\mathrm{CO}_{2} \uparrow$

In this step, the samples of pure NKN were disintegrated, wet-ground for $24 \mathrm{~h}$ and pressed under the pressure $15 \mathrm{MPa}$. Sintering was carried out in air for $2 \mathrm{~h}$ at $1443 \mathrm{~K}$. In case of the doped $\mathrm{NKN}$, high purity zinc oxide $\mathrm{ZnO}$ or cadmium oxide $\mathrm{CdO}$ of $1 \mathrm{wt} \%$ were added to the calcined KNN powder. Next the resulting mixtures were remilled a for $24 \mathrm{~h}$, dried, mixed with polyvinyl alcohol as a binder solution and uniaxially pressed into the discs of $6 \mathrm{~mm}$ diameter and $0.5 \mathrm{~mm}$ thickness. The pellets were placed on a platinum foil and covered with a powder of the same composition to prevent the volatilization of alkali elements. The sintering temperature for NKN $+1 \mathrm{wt} \%$ $\mathrm{ZnO}$ was $1383 \mathrm{~K}$ and for $\mathrm{NKN}+1 \mathrm{wt} \% \mathrm{CdO}$ was $1393 \mathrm{~K}$. The time of sintering was $2 \mathrm{~h}$.

The density of the sintered samples was measured by the Archimedes method. The X-ray measurements were performed by means of an X'Perrt PRO (PANalytical) diffractometer with horizontal goniometer making use of the filtering of $\mathrm{Cu}_{\mathrm{K} \alpha}$ radiation. The profile-fitting program FULLPROF [12] based on the Rietveld method was used to analyze and fit the spectra. The investigation of microstructure of the sintered ceramics was performed on fractures and polished sections. It was carried out by means of an electron scanning microscope with field emission Hitachi S4700 and with the microanalyses system Noran-Vantage, located in the Biology and Geology Science Scanning Laboratory of the Jagiellonian University. EDS (Energy-Dispersive X-ray Spectroscopy) 
was applied to investigate the homogeneity of the composition and EPMA (Electron Probe Microbeam Analysis) was applied to analyze the distribution of elements on the sample surface. For the measurements of dielectric properties silver electrodes were fixed on both surfaces of the sintered pallets. A computerized automatic system based on an LCR meter Hewlett Packard 4284A was used to measure dielectric spectra at frequencies from $20 \mathrm{~Hz}$ to $1 \mathrm{MHz}$ with an amplitude $2 \mathrm{kVm}^{-1}$ as a function of temperature. Prior to all measurements the samples were maintained at the temperature $800 \mathrm{~K}$ for 1 hour. Capacitances were recorded under the constant pressure for the successive heating and cooling cycles at the rate of $100 \mathrm{Kh}^{-1}$.

\section{Results and discussion}

The density of obtained $\left(\mathrm{Na}_{0.5} \mathrm{~K}_{0.5}\right) \mathrm{NbO}_{3}$ ceramics at the sintering temperature $1443 \mathrm{~K}$ reached the $94 \%$ value of the theoretical density (the theoretical density of pure NKN is $4.51 \mathrm{~g} / \mathrm{cm}^{3}$ ). The relative density values for the doped samples were also calculated, and for both compositions, density values are more than $94 \%$. The addition of $1 \mathrm{wt} \%$ CdO as a sintering aid increases the density by $3 \%$ and the sintering temperature decreases to $1393 \mathrm{~K}$. A high density with the value $4.28 \mathrm{~g} / \mathrm{cm}^{3}$ (which is about $95 \%$ of the theoretical density) and lowering the sintering temperature by $60 \mathrm{~K}$ were achieved by using $1 \mathrm{wt} \% \mathrm{ZnO}$.

The SEM analysis showed (Figure 1) that the samples are perfectly sintered and a small amount of oxide sintering aids have an effect on the morphology of NKN

(a)
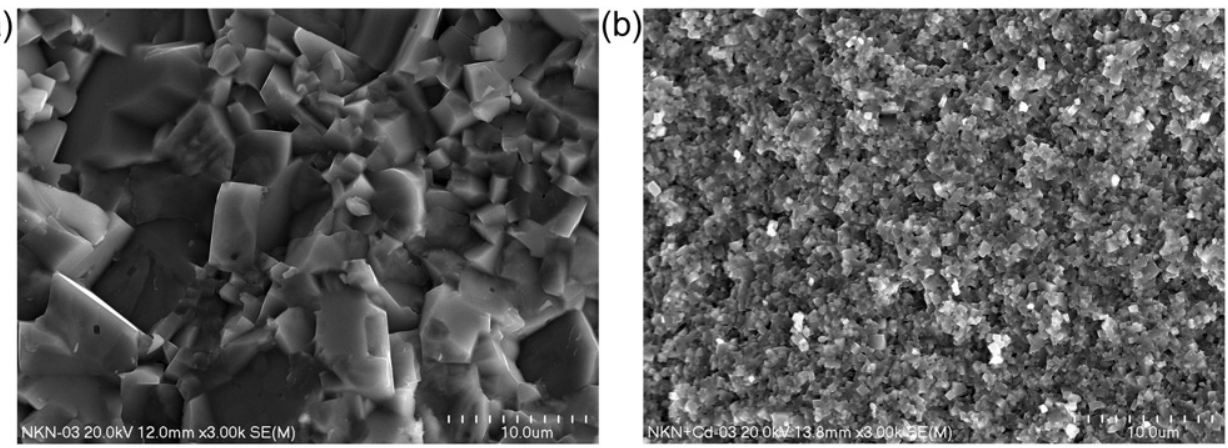

(c)

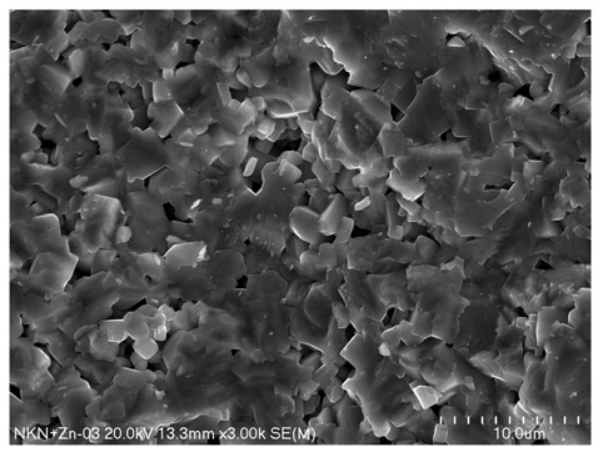

Figure 1. The SEM micrographs of the fractured surface of the NKN (a), NKN $+1 \mathrm{wt} \% \mathrm{CdO}$ (b) and NKN $+1 \mathrm{wt} \% \mathrm{ZnO}$ (c) samples (mgn. 3 000). 


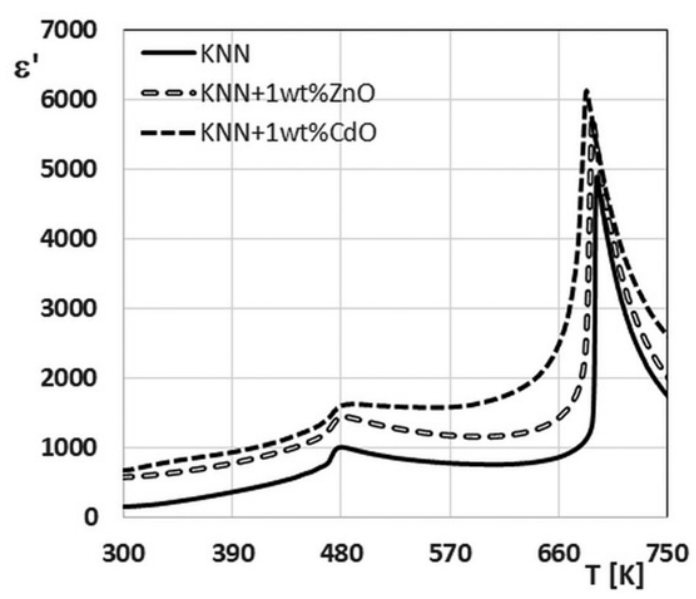

Figure 2. The temperature dependence of real part of complex dielectric permittivity $\left(\varepsilon^{\prime}\right)$ for NKN, NKN $+1 \mathrm{wt} \% \mathrm{CdO}$ and $\mathrm{NKN}+1 \mathrm{wt} \% \mathrm{ZnO}$ samples $(f=0.1 \mathrm{MHz})$.

ceramics. The surface of the fracture goes along grains, as well as along boundaries between the grains. The fracture has a fragile nature and the crystalline structures are observed in grains. A large difference in grain sizes is visible using admixtures, especially $\mathrm{CdO}$. $\mathrm{CdO}$ additive causes a significant reduction of grain size to an average size of $1.5 \mu \mathrm{m}$, which can be associated with the grain growth in the sintering process induced by the liquid phase of $\mathrm{CdO}$ (the melting point is $1173 \mathrm{~K}$ ) [13]. The addition of $\mathrm{ZnO}$ gives a homogenous microstructure with an average grain size of $4 \mu \mathrm{m}$, which can be explained by a lower sintering temperature. The EDS investigation confirmed the high purity and the expected qualitative composition. XRD results showed that the admixtures do not significantly affect the crystallographic structure and all examined samples has a pure perovskite structure with the monoclinic symmetry, which is in full agreement with other studies $[10,14]$.

The temperature dependence of the real part of the electric permittivity $\left(\varepsilon^{\prime}\right)$ obtained at $0.1 \mathrm{MHz}$ for the NKN, NKN $+1 \mathrm{wt} \% \mathrm{CdO}$ and $\mathrm{NKN}+1 \mathrm{wt} \% \mathrm{ZnO}$ ceramic samples was presented in Figure 2. The maximum of dielectric permittivity is observed at the temperatures of $691 \mathrm{~K}, 688 \mathrm{~K}$ and $682 \mathrm{~K}$ for NKN, NKN + 1wt\% ZnO and NKN + $1 \mathrm{wt} \% \mathrm{CdO}$ respectively, while a classic paraelectric - ferroelectric phase transition with a simultaneous change in the structure from cubic to tetragonal occurs. A significant increase in maximum value of $\varepsilon^{\prime}$ was noticed. The further lowering of temperature leads to the next maximum of $\varepsilon^{\prime}(\mathrm{T})$ dependence at the temperature of $482 \mathrm{~K}$ for all specimens. However, this maximum value is about four times less than the value of the previous maximum. The reduction of phase transition temperature in samples can be explained by the formation of oxygen vacancies during the sintering process [15] according to Kröger and Vink equation:

$$
\mathrm{O}_{o} \rightarrow V_{o}^{*}+2 e^{\prime}+\frac{1}{2} \mathrm{O}_{2}
$$

where:

$O_{o}$ - an oxygen ion on regular site, 


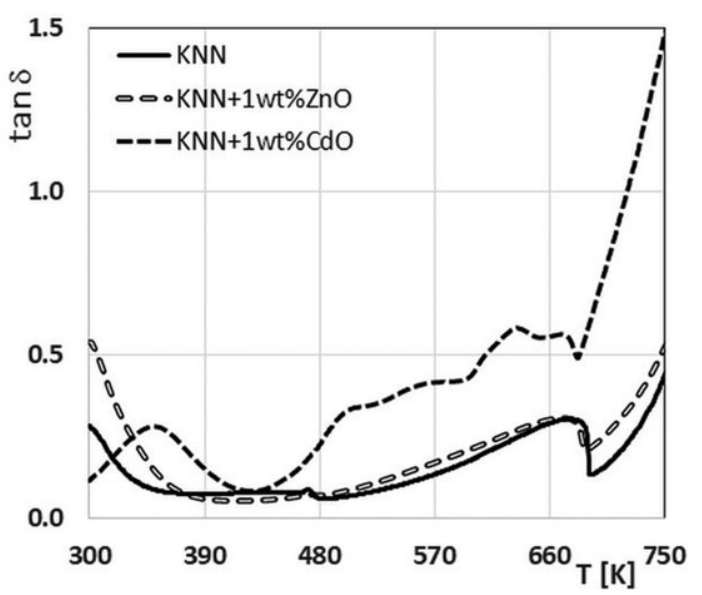

Figure 3. The temperature dependence of $\tan \delta$ for NKN, NKN $+1 \mathrm{wt} \% \mathrm{CdO}$ and $\mathrm{NKN}+1 \mathrm{wt} \% \mathrm{ZnO}$ samples $(f=0.1 \mathrm{MHz})$.

$V_{o}^{*}$ - oxygen vacancies with a double positive charge with respect to the regular lattice,

$e^{\prime}$ - electrons in the conductions band.

The constants $\mathrm{C}$ and $\mathrm{T}_{0}$ for the measuring field frequency of $0.1 \mathrm{MHz}$ and for the KNN sample were appointed based on a linear regression procedure. Their values are $1.54 \cdot 10^{5} \mathrm{~K}$ and $666 \mathrm{~K}$, respectively. Testing the validity of the Curie-Weiss law for NKN $+1 \mathrm{wt} \% \mathrm{ZnO}$ and $\mathrm{NKN}+1 \mathrm{wt} \% \mathrm{CdO}$ ceramics showed that values of Curie-Weiss constant and Curie-Weiss temperature are $4 \cdot 10^{5} \mathrm{~K}$ and $641 \mathrm{~K}$ and $3.7 \cdot 10^{5} \mathrm{~K}$ and $614 \mathrm{~K}$, respectively, and display the greatest differences compared to the pure potassium sodium niobate.

The Figure 3 shows the temperature dependence of dielectric loss tangent $\tan \delta$ during the cooling process. For all the studied ceramics in temperatures above the phase transition temperatures (in the paraelectric phase), a rapid increase in dielectric loss tangent values associated with an increase of electrical conductivity of the sample is observed. The appearance of a local maximum of $\tan \delta$ is associated with a loss of domain structure and the disappearance of the spontaneous polarization (the reorientation of the spontaneous polarization in alternating field gives rise to a current of dielectric losses). The energy losses for sample $\mathrm{NKN}+1 \mathrm{wt} \% \mathrm{CdO}$ are significantly higher compared to those of $\mathrm{NKN}$ and $\mathrm{NKN}+1 \mathrm{wt} \% \mathrm{ZnO}$. The Figure 4 presents the temperature changes of the real part of electric conductivity $\sigma^{\prime}$. In the phase transition temperature region for each specimen, the electric conductivity reaches a local maximum. This has been explained by Heywang $[16,17]$ who predicted such behavior based on the acceptor state density at the grain boundaries, the charge carrier density and the energy gap between the conduction band and the acceptor levels.

The minimum values of electrical conductivity are the result of the change in the nature of the conduction mechanism: from a tunnel into a hopping mechanism [18], that is the change from a short-range into a long-range mechanism. The transition temperature between the tunneling and the hopping regimes approximately agrees with the minimum of the curve $\ln \sigma^{\prime}$ versus 1000/T [18]. The activation energy of electric 


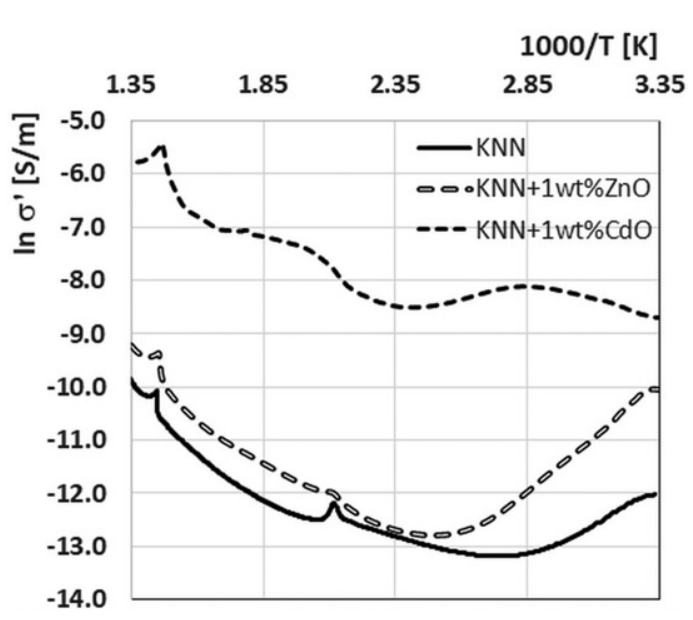

Figure 4. The temperature dependence of the a.c. electric conductivity at frequency $0.1 \mathrm{MHz}$.

conductivity in the ferroelectric state was calculated and the obtained values were as follows: $1.45 \mathrm{eV}, 1.24 \mathrm{eV}, 1.12 \mathrm{e} \mathrm{V}$ for NKN, NKN $+1 \mathrm{wt} \% \mathrm{ZnO}$ and $\mathrm{NKN}+1 \mathrm{wt} \% \mathrm{CdO}$, respectively.

\section{Conclusions}

$\mathrm{NKN}, \mathrm{NKN}+1 \mathrm{wt} \% \mathrm{CdO}$ and $\mathrm{NKN}+1 \mathrm{wt} \% \mathrm{ZnO}$ ceramics were obtained by a solid state synthesis from oxides and carbonates The addition of $1 \mathrm{wt} \% \mathrm{CdO}$ and $\mathrm{ZnO}$ oxides improves the densification and has a significant influence on the sintering temperature. The surface morphological features of the ceramics appeared to be quite sensitive to the amount of $\mathrm{ZnO}$ and $\mathrm{CdO}$ content. A good homogeneity of the microstructures and a small degree of porosity were observed. The obtained dielectric results demonstrate that the maximum value of dielectric permittivity increased but the value of the phase transition temperature decreased for $\mathrm{NKN}+1 \mathrm{wt} \% \mathrm{ZnO}$ and $\mathrm{NKN}+1 \mathrm{wt} \% \mathrm{CdO}$ samples in comparison with $\mathrm{Na}_{0.5} \mathrm{~K}_{0.5} \mathrm{NbO}_{3}$ obtained with the use of the conventional method. The analysis of the experimental data shows that the a.c. conductivity changes with $\mathrm{ZnO}$ and $\mathrm{CdO}$ addition and indicates that the transport mechanism is grounded on hopping of carriers between localized electron states.

\section{References}

1. H. D. Megaw, The seven phases of sodium niobate, Ferroelectrics. 7 (1), 87 (1974). DOI: $10.1080 / 00150197408237956$.

2. L. E. Cross, and B. J. Nicholson, The optical and electrical properties of single crystals of sodium niobate, Phil. Mag. 46 (376), 453 (1955). DOI: 10.1080/14786440508520582.

3. G. Shirane, R. Newnham, and R. Pepinsky, Dielectric properties and phase transitions of $\mathrm{NaNbO}_{3}$ and (Na,K)NbO 3 , Phys. Rev. 96 (3), 581 (1954). DOI: 10.1103/PhysRev.96.581.

4. J. Macutkevic, A. Molak, and J. Banys, Dielectric properties of $\mathrm{NaNbO}_{3}$ ceramics, Ferroelectics. 479 (1), 48 (2015). DOI: 10.1080/00150193.2015.1011916.

5. A. W. Hewat, Cubic-tetragonal-orthorhombic-rhombohedral ferroelectric transitions in perovskite potassium niobate: Neutron powder profile refinement of the structures, J. Phys. C: Solid State Phys. 6 (16), 2559 (1973). DOI: 10.1088/0022-3719/6/16/010. 
6. T. J. Nitta, Properties of sodium-lithium niobate solid solution ceramics with small lithium concentrations, J Am Ceram. Soc. 51, 626 (1968).

7. W. Smiga, Garbarz-Glos, B. Structural Mechanical, Properties of ceramic solid solutions $\mathrm{Na}_{1-}$ ${ }_{\mathrm{x}} \mathrm{Li}_{\mathrm{x}} \mathrm{NbO}_{3}$ for $\mathrm{x} \leq 0.06$, Ferroelectrics. 377, 137 (2008). DOI: 10.1080/00150190802523768.

8. L. A. Reznichenko et al., Dielectric and piezoelectric properties of $\mathrm{NaNbO}_{3}$-based solid solutions, Inorg Mater. 39 (2), 139 (2003). DOI: 10.1023/A:1022194512814.

9. R. J. D. Tilley, Perovskites: Structure-Property Relationships (John Wiley \& Sons, Chichester, 2016).

10. I. Smeltere et al., Lead-free $\left(\mathrm{Na}_{0.5} \mathrm{~K}_{0.5}\right) \mathrm{NbO}_{3}$ based solid solution, Integr. Feroelectrics. 108 (1), 46 (2009). DOI: 10.1080/10584580903324063.

11. B. Malic et al., Alkaline-earth doping in based piezoceramics, J. Eur. Ceram. Soc. 25 (12), 2707 (2005). DOI: 10.1016/j.jeurceramsoc.2005.03.127.

12. J. Rodriguez-Carvajal, Abstract satellite meeting on powder diffraction. Congr. Int. Union of Crystallography. Toulouse, France, 1990.

13. R. Zuo, J. Rodel, R. Chen, and L. Li, Sintering and electrical properties of lead free $\left(\mathrm{Na}_{0.5} \mathrm{~K}_{0.5}\right) \mathrm{NbO}_{3}$ piezoelectric ceramics, J. Am. Ceram. Soc. 89 (6), 2010 (2006). DOI: 10.1111/j.1551-2916.2006.00991.x.

14. J. Tellier et al., Crystal structure and phase transitions of sodium potassium niobate perovskites, Solid State Sci. 11 (2), 320 (2009). DOI: 10.1016/j.solidstatesciences.2008.07.011.

15. J. G. Fisher et al., Structural changes in potassium sodium niobate ceramics sintered in different atmosperes, J Alloys Comp. 479 (1-2), 467 (2009). DOI: 10.1016/j.jallcom.2008.12.100.

16. W. Heywang, Barium titanate as a semiconductor with blocking layers, Sol State Electron. 3 (1), 51 (1961). DOI: 10.1016/0038-1101(61)90080-6.

17. W. Heywang, Resistivity anomaly in doped barium titanate, J. Am. Ceram. Soc., 47 (10), 484 (1964). DOI: 10.1111/j.1151-2916.1964.tb13795.x.

18. H. Böttger, and V. V. Bryksin, Hopping Conduction in Solids (Academie-Verlag, Berlin, 1985).

Institute of Solid State Physics, University of Latvia as the Center of Excellence has received funding from the European Union's Horizon 2020 Framework Programme H2020-WIDESPREAD-01-2016-2017TeamingPhase2 under grant agreement No. 739508, project CAMART ${ }^{2}$ 